\title{
CARACTERÍSTICAS TERMOQUÍMICAS DA PIRÓLISE DO CAROÇO DE MANGA
}

\author{
L. A. ANDRADE ${ }^{1 *}$, L. G. VIEIRA ${ }^{1}$, M. A. S. BARROSO ${ }^{1}$ \\ ${ }^{1}$ Universidade Federal de Uberlândia, Faculdade de Engenharia Química \\ "e-mail: laianeng@gmail.com
}

\begin{abstract}
RESUMO
O objetivo desse trabalho foi investigar as características termoquímicas do tegumento de manga Ubá e sua aplicabilidade no processo de pirólise. De forma geral, os resíduos lignocelulósicos, tais como o tegumento de manga, são investigados por meios de análises padrões que incluem termogravimetria, análise imediata e elementar, poder calorífico, composição química, dentre outras. No presente trabalho algumas dessas análises foram utilizadas a fim de se determinar aspectos da termoconversão do tegumento de manga Ubá. Como resultado da análise imediata observou-se que a biomassa estudada apresentou um bom indicativo para formação de produtos líquidos, alto teor de voláteis $(94,0 \%)$ e baixos teores de cinzas $(0,8 \%)$. Os termogramas obtidos via análise termogravimétrica possibilitaram uma melhor compreensão da pirólise lenta do tegumento de manga. Por fim os resultados da pirólise analítica sinalizaram que a temperatura de $500^{\circ} \mathrm{C}$ seria a mais adequada para geração de voláteis, sendo que para tal temperatura os produtos majoritários foram o ácido acético e a classe dos compostos fenólicos.
\end{abstract}

\section{INTRODUÇÃO}

A avaliação das características termoquímicas da biomassa é um dos métodos requeridos para predizer a viabilidade de sua utilização em um processo de termoconversão (GREENHALF et al., 2012). Segundo Park et al. (2012), além das condições do processo, a qualidade dos produtos gerados na pirólise bem como seu rendimento, estão intimamente ligados ao tipo de biomassa utilizado.

Dessa forma, o conhecimento das características de uma biomassa em particular pode ser útil para se determinar as melhores condições operacionais e otimizar o processo de pirólise.
Nesse sentido diversos resíduos agroindustriais estão sendo investigados como biom assa para o processo de pirólise, tais como: bagaço de cana de açúcar (CAMARGO, 2006; MESA et al., 2004), palha de cana-de-açúcar (SAMANIEGO, 2007), serragem de eucalipto (CARDOSO, 2004) , capim elefante (GÓMEZ, 2002; MESA et al., 2004), casca de arroz (NATARAJAN et al., 2009). Porém ainda existem poucos relatos na literatura para uma infinidade de resíduos agroindustriais, as denominadas biomassas não convencionais (ODETOYEA, et al.,2012), dentre as quais se destaca o caroço manga. Somente na região do Triângulo Mineiro, na cidade de Araguari, são descartados $1300 \mathrm{t}$ /ano deste resíduo da manga.

A maior parte dos trabalhos presentes na literatura relacionados à manga é sobre a qualidade e trata-se da caracterização das 
polpas, aproveitamento dos resíduos produzidos pela indústria como, por exemplo, subprodutos da extração do suco, semente e casca, visando à extração de compostos bioativos (enzimas, compostos fenólicos, carotenóides, vitaminas, pectina) e emprego do amido presente na semente da manga para a produção de glicose (MEIRELES, 2011).

$\mathrm{O}$ caroço de manga é basicamente constituído de duas principais partes: a mais interna, denominada amêndoa, e a parte mais externa, que cobre a amêndoa, denominada de tegumento. O tegumento é conhecido por ter um alto conteúdo de lignina, celulose e hemicelulose.

Isto posto, este trabalho relata as características da termoconversão do tegumento de manga e avalia seu potencial como matéria-prima para geração de bio-óleo.

\section{MATERIAIS E MÉTODOS}

\subsection{Preparo da biomassa}

A matéria-prima utilizada foi fornecida pela empresa Maguary Ltda (Araguari, Minas Gerais). A espécie investigada foi a Ubá ( $M$. indica $L$ ), sendo que apenas seu tegumento foi aproveitado neste estudo, devido as suas características químicas.

As amostras de tegumento de manga formam trituradas e peneiradas. Com intuito de se minimizar a resistência à transferência de massa e calor, foi selecionado um tamanho pequeno de partícula estando o diâmetro médio de peneira na faixa $0,177<\mathrm{dp}(\mathrm{mm})<$ 0,354 .

\subsection{Análise Elementar e Imediata}

Para análise elementar, onde se determinou os teores de carbono, hidrogênio, nitrogênio, foi utilizado o equipamento CHNS/O 2400 da Perkin Elmer. A análise imediata foi realizada segundo as normas da ASTM.

\subsection{Análise Química}

O conteúdo de hemicelulose, celulose e lignina foi determinado de acordo com as normas da TAPPI.

\subsection{Análise termogravimétrica}

As análises termogravimétricas foram realizadas utilizando o analisador termogravimétrico da marca Shimadzu DTG 60. Os testes foram realizados nas seguintes condições: taxas de aquecimento de 5, 10, 20, $30^{\circ} \mathrm{C} / \mathrm{min}$; atmosfera inerte de nitrogênio; fluxo de gás de $50 \mathrm{~mL} / \mathrm{min}$; massa da amostra de aproximadamente $10 \mathrm{mg}$ e faixa de temperatura de 30 a $900^{\circ} \mathrm{C}$.

\subsection{Poder calorífico}

O poder calorífico da biomassa foi determinado em uma bomba calorimétrica IKAC2000, baseado no método NBR 8633/NBR 11956.

\subsection{Pirólise analítica}

As análises de micropirólise foram realizadas empregando um micro-pirolisador Pyroprobe 5200 da CDS e o cromatógrafo gasoso acoplado ao espectrômetro de massas GC/MS QP 2010 plus da Shimadzu. Os testes foram feitos em duplicata para as temperaturas de $350^{\circ} \mathrm{C}, 500^{\circ} \mathrm{C}$ e $700^{\circ} \mathrm{C}$ a uma taxa de aquecimento de $20^{\circ} \mathrm{C} / \mathrm{ms}$ e tempo de residência de $30 \mathrm{~s}$.

\section{RESULTADOS E DISCUSSÃO}

\subsection{Análises elementar e imediata}

Os resultados obtidos para as análises elementar e imediata estão discriminados na Tabela 1.

Com relação à análise elementar o tegumento de manga Ubá apresentou uma quantidade apreciável de carbono e hidrogênio, sendo a proporção dos dois juntos superior à de oxigênio. Está característica pode ser vantajosa, pois quanto maiores os 
teores dos mesmos, melhor é a eficiência de queima (YU et al., 2002).

$\mathrm{O}$ teor de nitrogênio $(0,5 \%)$ mostrouse abaixo do comumente encontrado para diversos resíduos agroindustriais, tais como: farelo de trigo $(2,34 \%)$, casca de café $(2,53 \%)$, casca de feijão $(2,64 \%)$ (OMAR et al., 2011) e bagaço de cana $(0,89)$ (DAS et al., 2004). Baixos valores de nitrogênio são desejáveis em biocombustíveis, uma vez que ajudam a reduzir a liberação de óxidos de nitrogênio (NOx) para o ambiente.

Tabela 1- Resultados da análise elementar e imediata.

\begin{tabular}{|l|c|}
\hline Análise Elementar & \% base seca \\
\hline Carbono $(\mathrm{C})$ & 45,95 \\
\hline Hidrogênio $(\mathrm{H})$ & 6,02 \\
\hline Nitrogênio $(\mathrm{N})$ & 0,50 \\
\hline Enxofre $(\mathrm{S})$ & 0,46 \\
\hline Oxigênio $(\mathrm{O})$ & 46,67 \\
\hline Análise Imediata & $\%(\mathrm{~m} / \mathrm{m})$ \\
\hline Umidade & $4,87 \pm 0,06$ \\
\hline Voláteis & $94,33 \pm 0,39$ \\
\hline Cinzas & $0,800 \pm 0,001$ \\
\hline Carbono fixo & 0,78 \\
\hline
\end{tabular}

Ainda pela análise da Tabela 1 nota-se que a biomassa em estudo apresentou um teor significativo de voláteis $(94,0 \%)$ e um baixo teor de cinzas $(0,8 \%)$. Resultados similares para as cinzas foram quantificados por Henrique et al. (2013), que encontrou o valor de $1,000 \pm 0,015 \%$ para o tegumento da manga Ubá. Tal fato sinaliza que o tegumento da manga Ubá pode ter um importante potencial na geração de bio-óleo, graças ao alto conteúdo de voláteis e baixo teor de cinzas.

\subsection{Análise química e poder calorífico}

$\mathrm{O}$ valor do poder calorífico indica o potencial total de energia disponível na biomassa. Conforme a Tabela 2, o valor encontrado para o tegumento de manga foi de $18,54 \mathrm{MJ} / \mathrm{kg}$, sendo semelhante ao encontrado para diversos resíduos lignocelulósicos e inclusive superior a alguns resíduos como bagaço de cana, palha de cana, casca de arroz, que apresentaram valores de $15,9 \mathrm{MJ} / \mathrm{kg}$ (VIEIRA, 2013), 16,42 MJ/kg (FERREIRA, 2012), 16,35 $\mathrm{MJ} / \mathrm{kg}$ (DINIZ et al.,2004), respectivamente

Tabela 2 - Composição química da biomassa e poder calorífico

\begin{tabular}{|l|l|}
\hline Análise química & $\%(\mathrm{~m} / \mathrm{m})$ \\
\hline Lignina & 25,12 \\
\hline Celulose & 49,98 \\
\hline Hemicelulose & 21,00 \\
\hline Poder calorífico $(\mathrm{MJ} / \mathrm{kg})$ & 18,58 \\
\hline
\end{tabular}

Ainda na Tabela 2 encontram-se reportados os valores da quantificação de lignina celulose e hemicelulose. Os teores de celulose e hemicelulose, para a biomassa residual deste estudo, somam mais de $50 \%$ dos componentes da biomassa, o que de acordo com Alisson et al. (2010) contribui para uma alta formação de voláteis.

Além disso, foi encontrado uma quantidade apreciável de lignina no tegumento de manga, apesar desse componente estar ligado a formação de char no processo de pirólise, um maior conteúdo de lignina tende a aumentar os valores caloríficos e também contribui para uma diminuição na temperatura de ignição do combustível formado.

\subsection{Análises termogravimétrica}

$\mathrm{Na}$ Figura 1 são apresentadas as curvas de perda de massa (TG) para as taxas de aquecimento estudadas $(5,10,20$ e $30^{\circ} \mathrm{C} / \mathrm{min}$ ).

Pela observação das curvas de TG, o primeiro evento foi predominantemente marcado pela etapa de secagem, que foi da temperatura ambiente à $100^{\circ} \mathrm{C}$, evidenciado pelo primeiro "ombro" das curvas.

Por volta de $250^{\circ} \mathrm{C}$ houve o início da degradação dos componentes da biomassa (início da segunda perda de massa). Segundo 
alguns autores (MANYÀ e ARAÙZO, 2008; RIEGEL et al., 2008), tem-se nesse evento a degradação principalmente da holocelulose (celulose e hemicelulose) que ocorre até por volta de $400^{\circ} \mathrm{C}$.

Figura 1- Curva experimental da perda de massa (TG) em função da temperatura, a diferentes taxas de aquecimento.

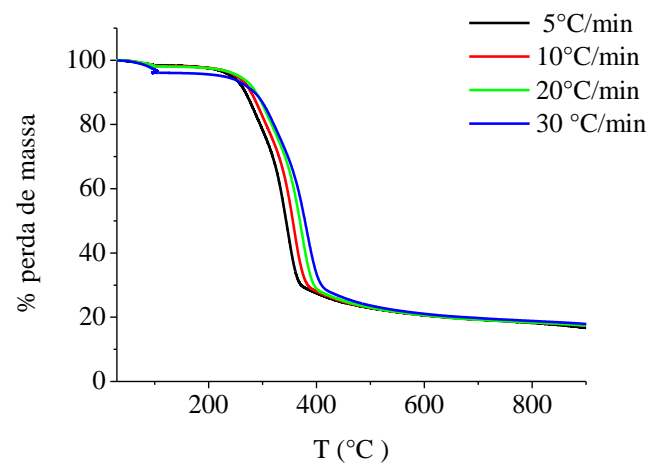

De acordo com Yang et al. (2007), a lignina decompõe-se na faixa de temperatura ambiente até $900^{\circ} \mathrm{C}$. Dessa forma, o último evento que ocorre seria majoritariamente a decomposição da lignina. Ainda pela análise dos termogramas observou-se uma formação de aproximadamente $75 \%$ de voláteis e por volta de $17 \%$ de char nas diversas taxas de aquecimento empregadas.

\subsection{Pirólise análitica}

As técnicas de separação dos produtos obtidos por pirólise podem ser financeiramente onerosas, sendo viável para os compostos predominantes, ou grupos funcionais que apresentem teores significativos (BRIDGWATER, 2004).

Tendo isto em vista o estudo da pirólise analítica, para os materiais ainda não avaliados (pois a distribuição dos produtos está intimamente ligada à composição da biomassa), torna-se um processo investigativo importante para se obter uma previsão do custo/benefício ou estimar a temperatura mais adequada para converter uma biomassa particular em um produto específico.
As Figuras 2, 3 e 4 apresentam os cromatrogramas da pirólise analítica do tegumento da manga Ubá, para as condições de temperatura de $350^{\circ} \mathrm{C}, 500^{\circ} \mathrm{C}$ e $700^{\circ} \mathrm{C}$, respectivamente.

Figura 2 - Cromatrograma da pirólise rápida do tegumento à $350^{\circ} \mathrm{C}$.

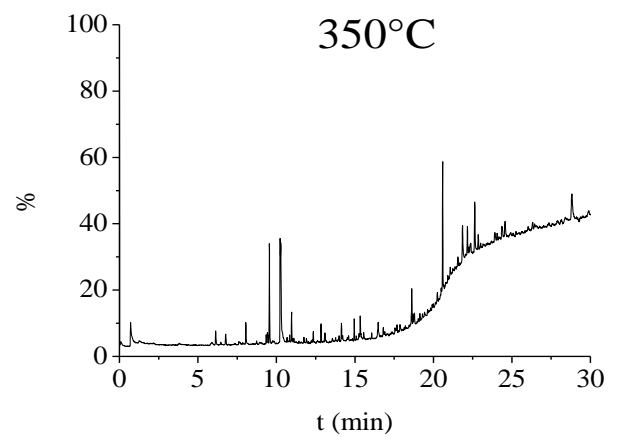

Figura 3 - Cromatrograma da pirólise rápida do tegumento à $500^{\circ} \mathrm{C}$

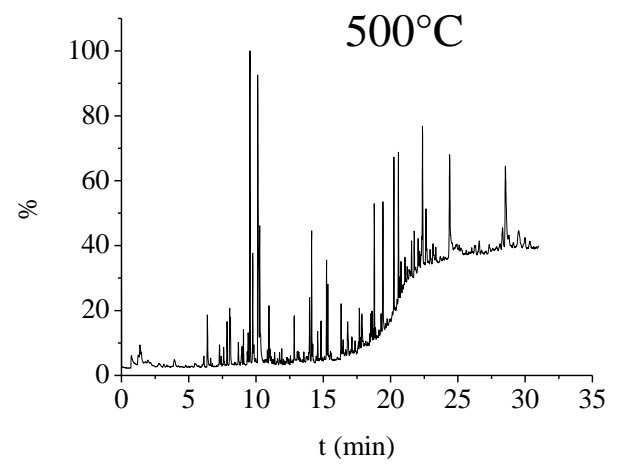

Figura 4 - Cromatrograma da pirólise rápida do tegumento à $700^{\circ} \mathrm{C}$.

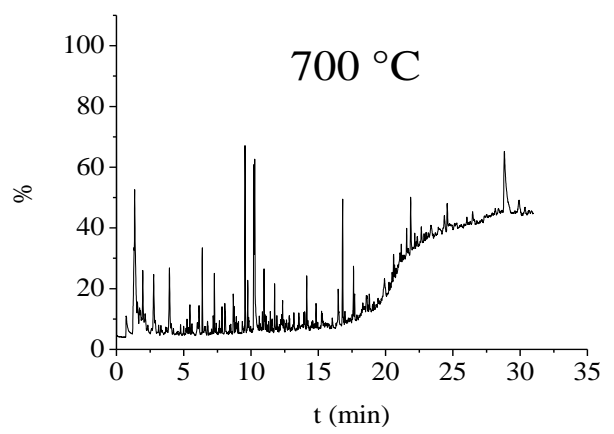


No caso da pirólise realizada à $350^{\circ} \mathrm{C}$ observou-se uma menor quantidade de picos e estes foram menos intensos quando comparados dom as demais temperaturas estudadas. Tal fato ocorre provavelmente porque nesse patamar de temperatura $\left(350^{\circ} \mathrm{C}\right)$ é degradada majoritariamente a hemicelulose, componente mais termoinstável presente na biomassa.

Com relação à celulose, a respectiva degradação foi observada (presença de pico detectados pelo Cromatógrafo Gasoso acoplado ao Massas GCMS) aperas para temperaturas superiores à $400^{\circ} \mathrm{C}$, similarmente ao relado por Soltes et al. (2014).Em temperaturas abaixo de $300^{\circ} \mathrm{C}$, sabe-se que a pirólise da celulose envolve principalmente reações de polimerização, formação de radicais livres, eliminação de água, formação de grupos carbonil, carboxil e hidroperóxidos, evolução do monóxido e dióxido de carbono e em última instância a formação de char (SHAFIZADEH et al., 1982). Segundo Boutin (1998), acima de $300^{\circ} \mathrm{C}$, uma série de reações químicas começa a ocorrer e são responsáveis pelo alto rendimento de produtos líquidos.

Para a pirólise do tegumento da manga Ubá à $350^{\circ} \mathrm{C}$, o principal produto químico formado foi o furfural. Este produto advém principalmente da fração da xilose advinda da hemicelulose. O furfural é um importante produto, servindo como matéria-prima de partida para o nylon 6.6, refino para motores a óleo, precursor de alguns plásticos e agente de limpeza de combustíveis líquidos (WERNER et al., 2014).

Com o aumento da temperatura de pirólise $\left(500^{\circ} \mathrm{C}\right)$, foi observada a formação de uma variedade maior de produtos, pela presença de uma quantidade mais elevada de picos de maior intensidade.

Nesta condição operacional os produtos majoritários foram o ácido acético e a classe de compostos fenólicos. Comumente o ácido acético é um composto abundante na fração aquosa do bio-óleo, podendo ser separada através de processos de destilação (CZERNIK, 2004).

O ácido acético é um ácido carboxílico que pode ser empregado na fabricação de garrafas e fibras (RASRENDRA et al., 2011).

Os compostos fenólicos também encontrados em quantidades significativas na pirólise à $500^{\circ} \mathrm{C}$ podem ser usados como resinas, aromatizantes na indústria alimentar, na fabricação de adesivos polímeros e também como intermediários na síntese de produtos farmacêuticos (ZILNIK e JAZBINSEK, 2012).

Por fim, a pirólise realizada à $700^{\circ} \mathrm{C}$ apresentou uma grande diversidade de produtos, porém em menor quantidade (menor intensidade dos picos). Acredita-se que nesta temperatura, houve um favorecimento da formação de produtos gasosos, em detrimento dos vapores condensáveis (bio-óleo). O favorecimento da formação de produtos gasosos à $700^{\circ} \mathrm{C}$ também foi verificada por Gao et al. (2013) durante a pirólise analítica da serragem na qual os produtos majoritários foram gasosos $\left(\mathrm{CH}_{4}, \mathrm{CO}\right.$ e $\left.\mathrm{CO}_{2}\right)$.

Dentre os principais compostos orgânicos formados à $700^{\circ} \mathrm{C}$, puderam ser constatados o 1,3-pentadieno, o ácido acético e o furfural. $\mathrm{O}$ 1,3-pentadieno é um hidrocarboneto linear com 5 carbonos, inflamável e volátil, usado como monômero na produção de plásticos, resinas e adesivos. Atualmente o 1,3-pentadieno é produzido comercialmente através do etileno pelo craqueamento catalítico da nafta (ACTON, 2013).

Tendo em vista o exposto, concluiu-se que a pirólise do tegumento da manga Ubá à $500^{\circ} \mathrm{C}$ foi a condição operacional mais favorável para a formação de vapores condensáveis (bio-óleo).

A pirólise à $350^{\circ} \mathrm{C}$ do tegumento da manga Ubá, apesar de produzir poucos compostos orgânicos, também representa uma 
condição operacional favorável sob a óptica do consumo de energia, pois foi capaz de produzir furfural a partir das condições térmicas mais brandas, dentre as estudadas.

\section{CONCLUSÕES}

O Tegumento de manga foi caracterizado com intuito de avaliar sua adequação como matéria-prima potencial para a produção de bio-óleo.

A análise imediata demonstrou que a biomassa estudada apresenta um bom indicativo para formação de produtos líquidos, alto teor de voláteis $(94,0 \%)$ e baixos teores de cinzas $(0,8 \%)$.

A análise de TG gerou resultados que possibilitaram entender o comportamento da pirólise lenta do tegumento de manga.

Por fim os resultados da pirólise analítica demonstraram que, a temperatura de $500^{\circ} \mathrm{C}$ mostrou-se a mais adequada para produção de líquidos. Na temperatura de $350^{\circ} \mathrm{C}$, teve-se o menor custo energético e foi possível a formação de furfural. A pirólise à $700^{\circ} \mathrm{C}$ proporcionou a formação majoritária do 1,3-pentadieno, um importante precursor químico de interesse industrial.

\section{NOMENCLATURA}

ASTM - American Society for Testingand Materials

dp - Diâmetro de partícula [mm]

TAPPI - Technical Association of the Pulp and Paper Industry

\section{AGRADECIMENTOS}

Os autores deste trabalho agradecem à FAPEMIG (CRA-APQ-01931-13), ao CNPq (Proj. 422749/2013-7) e ao Laboratório de Separação e Energias Renováveis (LASER) da FEQUI/UFU

\section{REFERÊNCIAS}

ACTON, A. Q. Aluminum Silicates. Advance s in Research and Application: Scholarly Editions 244 p, 2013.

ALLISON, G. G.; MORRIS, C.; LISTER, S. J.; SHIELD, I.; YATES, N.; BARRACLOUT, T.; DONNISON, I. S. Measurement of lignocellulose composition as a tool to understand how feed-stocks can be matched to conversion process. in $\mathrm{A} \mathrm{V}$ Bridgwater (ed.), Proceedings of the Bioten Conference on Biomass Bioenergy and Biofuels 2010 . CPL Press , p.1-16, 2010.

BOUTIN, O.; FERRER, M.; LEDE, J. Radiant flash pyrolysis of cellulose evidence for the formation of short life time intermediate liquid species. J. Anal. Appl. Pyrol., v.47,p. 13-31,1998.

BRIDGWATER, A. V. Biomass fast pyrolysi s. Thermal Science., Downloaded from: http: //thermalscience. vin.bg.ac.yu/pdfs/20042/TS 22004Cl2.pdf , v.12, p.21-49, 2004.

CAMARGO, F. L. Estudo da pirólise rápida de bagaço de cana em reator de leito fluidizado borbulhante. 2006, 184p. Tese de Doutorado, EM/UNICAMP, Campinas, SP, 2006

CARDOSO, A. L. Pirólise lenta de serragem de eucalipto para obtenção de bio-óleo e carvão. 2004, 105p. Dissertação de mestrado. Pós-graduação em Química, Universidade Federal de Santa Maria - RS, 2004.

CZERNIK, S.; BRIDGWATER, A. V. Over view of applica tion ofbiomass fast pyrolysis oil. Energy Fuels, v.8, p.550-590, 2004.

DAS, P.; GANESH, A.; WANGIKAR, P., Influence of pretreatment for deashing of 
sugarcane bagasse on pyrolysis products, Biomass Bioenergy, v. 27, p. 445-457, 2004.

FERREIRA, R. A. R. Contribuição ao estudo cinético e balanço energético da pirólise autotérmica da palha de canade açúcar através de análises termogravi métricas e calorimetria. 2012, 80p. Disserta ção de Mestrado Uberlândia:UFU

GAO, N.; LI, A.; QUAN, C.; DU, L.; DUAN, Y. TG-FTIR and Py-GC-MS analysis on pyrolysis and combustion of pine sawdust. J. Anal. Appl. Pyrolysis, v.100, p. 26-32, 2013.

GÓMEZ, E. O. Estudo da pirólise rápida de capim elefante em leito fluidizado borbulhante mediante caracterização dos finos de carvão. 2002, 153p. Tese de doutorado. Faculdade de Engenharia Agrícola /UNICAMP, 2002.

GREENHALF, C.E.; NOWAKOWSKI, D.J.; BRIDGWATER, A.V.; TITILOYE, J.; YATE S, N., RICHIE; A.,SHIELD, I. Thermochemic al characterisation of straws and high yielding perennial grasses. Ind. Crops Prod. v.36, p.449-459, 2012.

HERIQUE, M. A; SILVÉRIO, H. A; FLAUZ INO, W. P.; PASQUINI, D. Valorization of an agro-industrial waste, mango seed, by the extraction and characterization of its cellulose nanocrystals. Journal of Environmental Ma nagement, v.121, p.202-209, 2013.

MANYÀ, J. J.; ARAÙZO, J. An alternative kinetic approach to describe the isothermal pyrolysis of micro-particles of sugar cane bagasse. Chemical Engineering Journal, v.139, p.549-561, 2008.

MEIRELES, C. S. Síntese e caracterização de membranas assimétricas de acetato de celulose obtido a partir da celulose do caroço de manga e do jornal. 2011, 93p. Tes e de Doutorado Uberlândia:UFU.

MESA-PÉREZ, J. M. Testes em uma Planta de Pirólise Rápida de Biomassa em Leito Fluidizado: Critérios para sua Otimiz ação. 2004, 162p. Tese de doutorado Universidade Federal de Campinas, Faculdad e de Engenharia Agrícola, Campinas, 2004.

ODETOYEA, T. E.; ONIFADEB, K .R.; AB UBAKARC, M. S. TITILOYEC, J.O. Thermo chemical characterisation of Parinari polyandra Benth fruit shell. Valverde Bioresour. Technol., v.109, p.163-172, 2012

OMAR, R.; IDRIS, A.; YUNUS, R.; KHALI D, K.; ISMA, M.I. Characterization of empty fruit bunch for microwave-assisted pyrolysis. Fuel, v.90, p.1536-1544, 2011

PARK, Y.; YOO, M.L.; LEE, H.W.; PARK, S.H.; JUNG, S.; PARK, S.; KIM, S. Effect of oper-ation conditions on pyrolysis characteristics of agricultural residues. Renew.Energ. v.42, p.125-130, 2012.

RASRENDRA， C. B.; GIRIUSTA， B.; BOVENKAMP, H.H.; WONKELMAN, J. G. M.; LEJENHORST, E.J.; VENDERBOSH, R.H.; WINDT, M.; MEIER, D.; HEERES, H. J. Recovery of acetic acid from an aqueous pyrolysis oil phase by reactive extraction using tri n octylamine. Chemical Engineerin g Journal, v.176-177, p. 244-252, 2011.

RIEGEL, I.; MOURA, A. B. D.; MORISSO, F. D. P.; MELLO， F. S. Thermogravimetric analysis of the pyrolysis of Acacia mearnsii de Wild. Harvested in Rio Grande do Sul, Brasil, R. Árvore, v.32, p.533-543, 2008 .

SAMANIEGO, M. R. P. Uso de biocombustível da pirólise rápida da palha 
de cana em um motor de ciclo Otto. 2007, 112p. Dissertação de Mestrado, PSE/UNICA MP, Campinas, SP, 2007.

SHAfiZADEH, F. Introduction to pyrolysis of biomass. J. Anal. Appl. Pyrol., v.3, p. 283-305, 1993.

SOLTES, E. J.; WILEY, A. T.; LIN, S. C. K. Biomass pyrolysis towards an understanding of its versatibility and potentials, Biotechnol. Bioeng. Symp. v.11, p.125-136,1981.

VIEIRA, C. S. Caracterização do bagaço de cana-de-açúcar e do bio-óleo produzido através do processo de pirólise rápida. 2013, 87p. Dissertação de Mestrado Uberlân dia:UFU.

WERNER, K.; POMMER L.; M. BROSTRÖ M. Thermal decomposition of hemicellulose. Journal of Analytical and Applied Pyrolysi s, v.xxx ,p. xxx-Xxx, 2014.

YANG, H.; YAN, R.; CHEN, H.; LEE, D. H.; ZHENG, C. Characteristics of hemicelluloses, cellulose and lignin pyrolysis. Energy Fuel. v.86, p.1781-1788, 2007.

YU, Y. H.; KIM, S. D.; LEE, J. M.; LEE, K. $\mathrm{H}$. Kinectic studies of dehydration, pyrolysis and combustion of paper sludge. Energy, v.27, p.457-469, 2002.

ZILNIK, L.F.; JAZBINSEK, A. recovery of renewable phenolic fraction from pyrolyisis oil. Separation and purification Technology, v. 86, p.157-170, 2012. 